\title{
Removal of Carbonyl-Containing Effluents by Photodegradation Using $\beta$-Carotene Embedded onto Zinc Oxide Particles
}

\author{
Bakari Chaka and Aloys Mosima Osano \\ Department of Mathematics, and Physical Sciences, School of Science and Information Sciences, Maasai Mara University, Narok \\ 20500, Kenya
}

\begin{abstract}
Environmental pollution especially in the form of effluent wastewater from industries has been a major challenge. Carbonyl-containing organic standards and sewage sample were effectively photo degraded. ZnO nanoparticles were prepared by emulsification of zinc-carbamate solution using $1 \mathrm{~N} \mathrm{NaOH}$ and grafted chemically by Molecular Layer Doping method at $180{ }^{\circ} \mathrm{C}$ with $\beta$-carotene extracted using methanol by refluxing at $50{ }^{\circ} \mathrm{C}$ at varying concentrations. Intrinsic and grafted $\beta$-carotene $\mathrm{ZnO}$ were characterized using FTIR (Fourier transform infrared spectroscopy) and their spectra differed in an additional peak at around 1,435 $\mathrm{nm}$ corresponding to the organ metallic bond Zn-C. UV-Vis spectra of the two composites indicated a blue shift in the grafted samples. This translated to a reduced band gap from $3.5 \mathrm{eV}$ to $3.4 \mathrm{eV}$. Comparison in the rates of photodegradation of pure organic compounds, organic effluents and color change of dyes was in the order $1 \%$ grafted, $0.5 \%$ grafted, intrinsic ZnO and blank sample. When $10.0 \mathrm{~mL}$ of sewerage water was photo degraded using both sunlight and UV-Lamp for 40 minutes, the amount of carbonyls present decreased by $28.5 \%$ for $\beta$-carotene grafted $\mathrm{ZnO}, 24.5 \%$ for intrinsic $\mathrm{ZnO}$ and $0.6 \%$ for a blank sample.
\end{abstract}

Key words: Intrinsic $\mathrm{ZnO}, \beta$-carotene, organic effluents, carbonyls, photo-degradation.

\section{Introduction}

Effluent organic pollution is a universal problem that affects aqua life. Most of these pollutants are long-chain natural products, acetogenic and alkaloidal in nature and their molecular structures are found coupled, with aromatics as well as coordination structures. For example, most textile dye effluents are released continuously, thus require a continuous controller [1]. Most are non-biodegradable thus have almost permanent effects that are encountered very slowly, mainly through bacteria action [2]. Dissolved oxygen in effluent waters is usually lower compared to clean water due to chemical and bio-chemical reactions that take place in the presence of these impurities [3]. Organisms in such water bodies are thus prone to

Corresponding author: Bakari Chaka, BSc Chemistry, research fields: wastewater treatment, food and nutrition, biofuels and biomass catalysis. asphyxiation and reduced fitness which can lead to their death. On the other hand, increased particulates as a result of impurities increase the turbidity level of wastewater, hindering light penetration into the water [4]. Photosynthesis of planktons in these waters is thus reduced. Substratum composition at the bottom of water bodies is also altered by settling particulates and organic matter.

Most of these compounds are coordinate compounds and also incorporate heavy metals in them. When these compounds are up taken by planktons, they are then ingested by fish and later by humans or other higher animals [5]. Some leach into nearby plants and can either affect the plant itself or its feeders. Increased levels of heavy metals in the body cause nerval and kidney disorders [3].

Over time, various methods have been employed to clean wastewater for domestic or industrial use. Unfortunately, most of the methods exploited have not 
yielded much. Actually, some traditional methods have been accused of transferring the pollutant matrix from one form to another, creating more harm than before. Some of the physical methods employed include carbon adsorption, reverse osmosis and ultrafiltration. While adsorption is quite effective, the method cannot work optimally for pollutants at very low concentration, not unless the active sites of the carbon are functionalized or expanded (which is expensive). Ultrafiltration and reverse osmosis are also quite expensive for most developing nations. Chemical methods used include coagulation, flocculation and ion exchange. Flocculation and coagulation by chemical agents are less effective for effluent removal while ion-exchange is quite expensive [6, 7].

With an ever-increasing human population, water treatment and recycling from effluents are very crucial [1]. Industrial effluent cleanup is therefore receiving more attention over time. Photochemical reactions using semiconductors like $\mathrm{TiO}_{2}$ and $\mathrm{ZnO}$ are currently being used [8]. To enhance its effectiveness, chemists have tried to induce doping on its nanosurfaces, thus opening more channels for other studies, since the grafted surfaces are not only good photo catalysts but also anti-oxidants and promote electrical conductivity. Photocatalysis using zinc oxide particles in the presence of light has been proven to degrade wastewater to simpler and relatively friendlier compounds such as $\mathrm{CO}_{2}, \mathrm{HCl}$ and water [6, 9].

$$
\begin{gathered}
\text { Dye }+\mathrm{OH} \bullet \rightarrow \text { degradation products } \\
\text { Dye }+\mathrm{H}^{+} \rightarrow \text { oxidation products } \\
\mathrm{CH}_{3} \mathrm{COOH}+2 \mathrm{H}_{2} \mathrm{O}+8 \mathrm{H}^{+} \rightarrow 2 \mathrm{CO}_{2}+8 \mathrm{H}^{+}[8]
\end{gathered}
$$

Zinc oxide used as a photocatalyst is gradually growing populace due to its multiple attributes. The compound is widely available making it cheap. Zinc oxide is also found in several forms, most of which have excellent physical and chemical characteristics. Zinc oxide reacts with most organic and inorganic chemicals at ambient conditions. Its band gap is wide enough and is naturally n-type semiconducting material [10, 11]. The compound is environment friendly and non-toxic. Zinc oxide has been used in numerous photovoltaic applications due to its extensive light absorbance [12, 13]. Its photocatalytic activity at low cost and using natural sunlight makes it a favorite compound for photovoltaic works [7, 14]. The band gap of zinc oxide particles ranges at about $3.36 \mathrm{eV}(\lambda=388 \mathrm{~nm}) . \beta$-carotene is a suitable dopant, as due to its conjugation system absorbs both UV and Vis-light just as $\mathrm{ZnO}$ [15].

With a rapidly increasing human population: natural resource index, there is more demand for cleaner water. Since the current water sources are slowly being depleted, it is pertinent for reclamation of the polluted water by cleaning it using cheap and efficient methods. Organic photocatalysis is one such method. This study purposed to minimize organic pollutants from wastewaters by use of photocatalysis using beta carotene powder embedded onto zinc oxide particles. Both beta carotene and zinc oxide can optimally absorb at normal sunlight wavelength. Beta carotene can easily be sourced from Opuntia stricta cacti, abundant in arid and semi-arid regions of southern part of Rift valley, Kenya.

\section{Materials and Methods}

\subsection{Experimental Design}

Beta carotene was prepared from cacti Opuntia stricta and carrot peels then characterized before grafting onto zinc oxide particles prepared by emulsification of zinc carbamate at alkaline conditions. The grafts were performed at high temperature of $150-180{ }^{\circ} \mathrm{C}$. Thereafter, the intrinsic and grafted zinc oxide particles were coated onto aluminium foil reactor and test analytes degraded. Standards of carbonyl containing organic compounds (formaldehyde and acetone) were run before samples of dyes (methyl blue and 2,4-DNP hydrazine) and sewage water samples were run. Effective carbonyl removal was tested using titration method and a $t$-test run to compare the rates of removal between intrinsic 
and grafted zinc oxide.

\subsection{Materials}

Chemicals: methanol, 98\% ethanol, toluene, $n$-hexane, zinc nitrate, urea, sodium hydroxide, acetone, formaldehyde, sodium bisulfite, methyl blue indicator and 2,4-dinitrophenyl hydrazine. All chemicals were from Sigma-Aldrich products.

Apparatus: - $10-360{ }^{\circ} \mathrm{C}$ Range Thermometer, $10 \mathrm{~mL}$ and $100 \mathrm{~mL}$ glass measuring cylinders, \#41 Whatmans filter papers, stirring rods, stop watch, 30 test-tubes, 5 droppers, 5 filter funnels, round bottomed flask, liebigs condenser with adapter, about $1.5 \mathrm{~m}^{2} 20$ mm thick aluminium sheet, 12 100-mL glass beakers.

Access to: analytical balance, source of heat, magnetic stirrer, gas syringe or gas flow meter, UV-Vis (UV-550; Jasco, Japan) and FTIR (Fourier transform infrared spectrometer), Shimadzu.

\subsection{Extraction of $\beta$-Carotene}

Solid carrot and cacti Opuntia stricta fruits paste (50 g) are run through 30 minutes in $150 \mathrm{~mL}$ methanol. (ratio 3:1) with samples taken and evaluated every fifth minute between 40 and $65{ }^{\circ} \mathrm{C}$. After $60{ }^{\circ} \mathrm{C}$, the paste extracted was dark orange with the sample extracted at $70{ }^{\circ} \mathrm{C}$ very dark in color. The samples were refrigerated then filtered using normal filter paper (size 41). The samples were initially tested by solubility in which case they were found to be soluble in benzene and hexane but insoluble in water [15]. Samples were stored in dark Thereafter, an FTIR spectra was run to confirm correspondence with library spectra.

\subsection{Preparation of ZnO Particles}

Zinc nitrate of mass $0.7 \mathrm{~g}$ and $0.2 \mathrm{~g}$ of urea was dissolved in $100 \mathrm{~mL}$ distilled water. Slowly the solution was stirred until the crystals fully dissolved. By now the solution is transparent. Three-five drops of $1 \mathrm{~N} \mathrm{NaOH}$ solution ( $0.5 \mathrm{~g}$ in $20 \mathrm{~mL}$ water) are added to adjust the solution to $\mathrm{pH}$ 12.0. As $\mathrm{NaOH}$ is added, the solution becomes turbid, producing a whitish cloudy precipitate. It was then heated for 15 minutes and a white dispersion that is slightly blue is seen. This slightly blue color indicates presence of nanoparticles. They were characterized using FTIR and UV-Vis.

\subsection{Sol-Gel Dipping Process to Coat $\beta$-Carotene Grafted Zinc Oxide on Aluminium Sheets}

An aluminium sheet of size 21 by $11 \mathrm{~cm}$ was cleaned by scrubbing the surface gently to remove any impurities or oxide layers on the surface. The cleaned sheet was then dipped in the grafted zinc oxide solution for about 10 minutes. The sheet was then gradually removed from the solution and air-dried for 2 hours [16]. This was repeated two more times for uniform coating thickness to be obtained.

\subsection{Preparation of $\beta$-Carotene Grafted Zinc Oxide Nanoparticles}

$\mathrm{ZnO}$ particles were grafted chemically by Molecular Layer Doping. Varying concentrations of $\beta$-carotene powder were calcinated and blown onto Zinc Oxide-NP solution coated on aluminium sheet at around $150{ }^{\circ} \mathrm{C}$ (annealing). Surface characterization was done using FTIR and UV-Vis spectrophotometers.

\subsection{Experimental Set-Up and Procedure}

A $\mathrm{ZnO}$ coated aluminium sheet was folded to make a continuous reactor of length $40 \mathrm{~cm}$ with an external diameter of $10 \mathrm{~cm}$ then folded to make an open cylinder. The ends were not joined together. The setup was inclined at an angle of around $10^{\circ}$ for slow movement of the test samples. The front side was connected to an overturned bottle from which the test samples will be flowing from. On the rear side a collecting glass was placed to collect the degraded samples.

\subsection{Analysis of Test Samples}

Ten (10) mL samples of $1 \mathrm{M}$ and 14.5 $\mathrm{M}$ acetone, 1 
M formaldehyde, 98\% ethanol and sewerage water were tested for the percentage of carbonyl groups present determined by titration using sodium bisulfite and $1 \mathrm{~N}$ alkali solution (caustic soda) before and after degradation in the above reactors for 40 minutes. The following formula was used:

$$
\% \mathrm{C}=\mathrm{O}=\left\{\left(V_{S}-V_{B /} W\right) \times N \times M / 1,000\right\} \times 100
$$

where $V_{s}$ is volume of titre, $V_{B}$ is volume of blank, $W$ is weight of alkali solution, $N$ is molar mass in $\mathrm{g} / \mathrm{mol}$ of test sample (carbonyl) and $M$ is concentration of titrating solution $\left(\mathrm{NaHSO}_{3}+\right.$ Test sample).

\section{Data Results and Discussions}

Beta carotene extracts were characterized for functional group as shown in Fig. 1 and below.

The major peaks in spectra (Fig. 1) are a trans-conjugated alkene at around $962 \mathrm{~nm}$, asymmetric stretching vibration of $\mathrm{CH}_{2}$ at $2,922 \mathrm{~nm}$, in-plane $\mathrm{CH}$ at $1,033 \mathrm{~nm}$ and $\mathrm{CH}_{2}$ scissoring at 1445 $\mathrm{nm}$.

The major peaks in Fig. 2 are a Zn-O bond at $460-560 \mathrm{~nm}, \mathrm{O}-\mathrm{H}$ vibration at around 3,420 $\mathrm{nm}$ and specifically for nanoparticles due to absorption at early UV region, a stretch at 2,370 $\mathrm{nm}$. The UV-Vis spectra of $\mathrm{ZnO}$ nanoparticles indicate absorption at around $330 \mathrm{~nm}$ [11].

The major peaks (in Fig. 3) in FTIR of p-grafted $\mathrm{ZnO}$ are $\mathrm{Zn}-\mathrm{O}$ at $460-560 \mathrm{~nm}$, O-H vibration at around 3,420 nm, an absorption at around 2,370 nm and an additional organometallic bond, Zn-C at 1,435 $\mathrm{nm}[8,11] \mathrm{UV}-\mathrm{Vis}$ spectrum of p-grafted $\mathrm{ZnO}$ showing a slight enhanced absorption (300-355 nm) from that of intrinsic $\mathrm{ZnO}$.

From FTIR spectra in Fig. 3, the major peaks are a $\mathrm{Zn}-\mathrm{O}$ band stretch at around 460-560 $\mathrm{nm}$ and an O-H band at around $3,420 \mathrm{~nm}$. An extra band is inserted around 1,458 $\mathrm{nm}$ corresponding to addition of the organometallic bond, Zn-C. This illustrates the doping effect of the carotenoids.

From UV-Vis spectrum, the nanocomposites are seen to absorb radiations of this wavelength at the region between 300-360 nm. One can thus conclude that they can absorb early UV (A and B) which is abundantly available in the natural sunlight and is significant for photo degradation of industrial wastewaters. The UV-Vis spectrum of grafted $\mathrm{ZnO}$ is

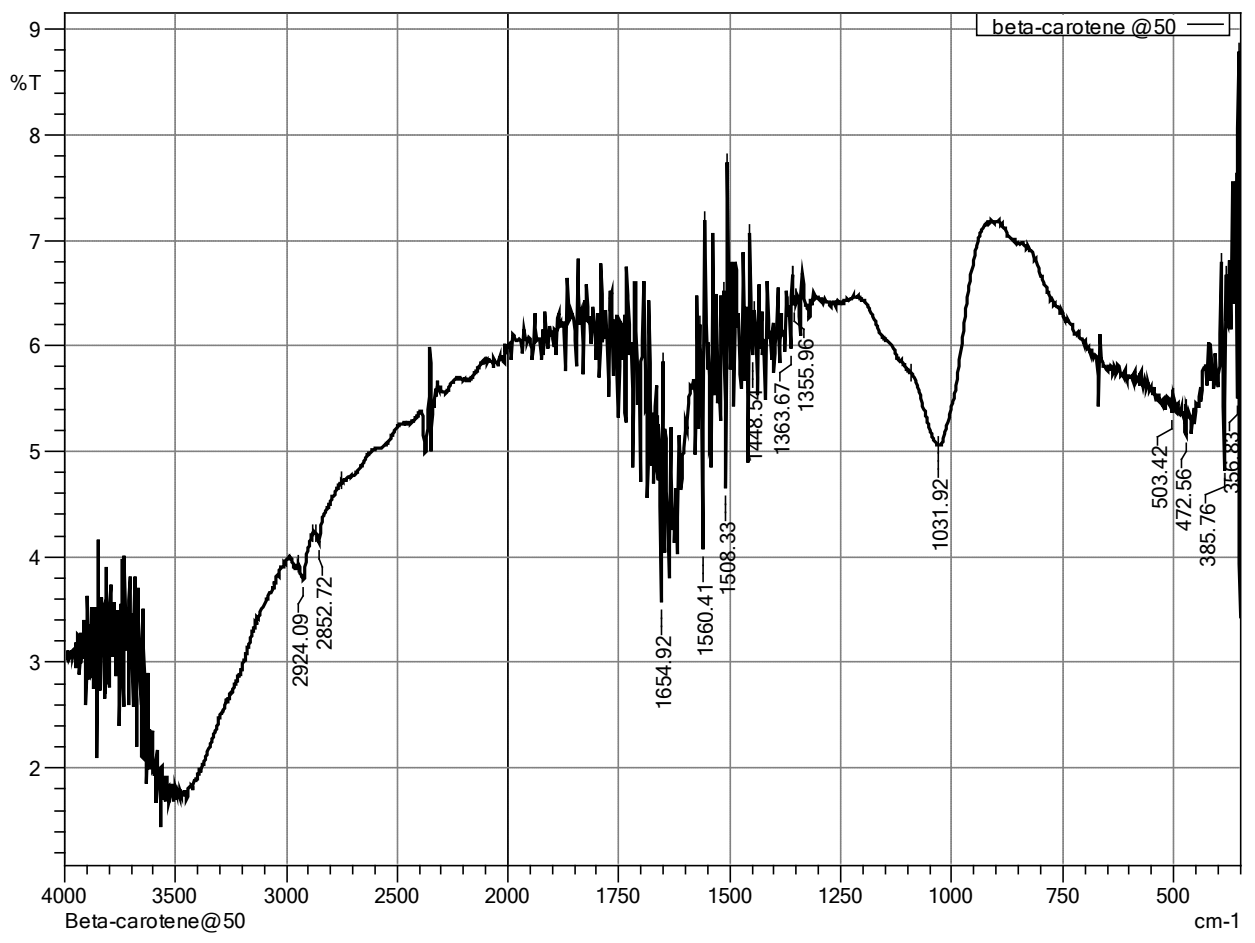


Fig. 1 FTIR spectra of $\beta$-carotene extracted at $50^{\circ} \mathrm{C}$.
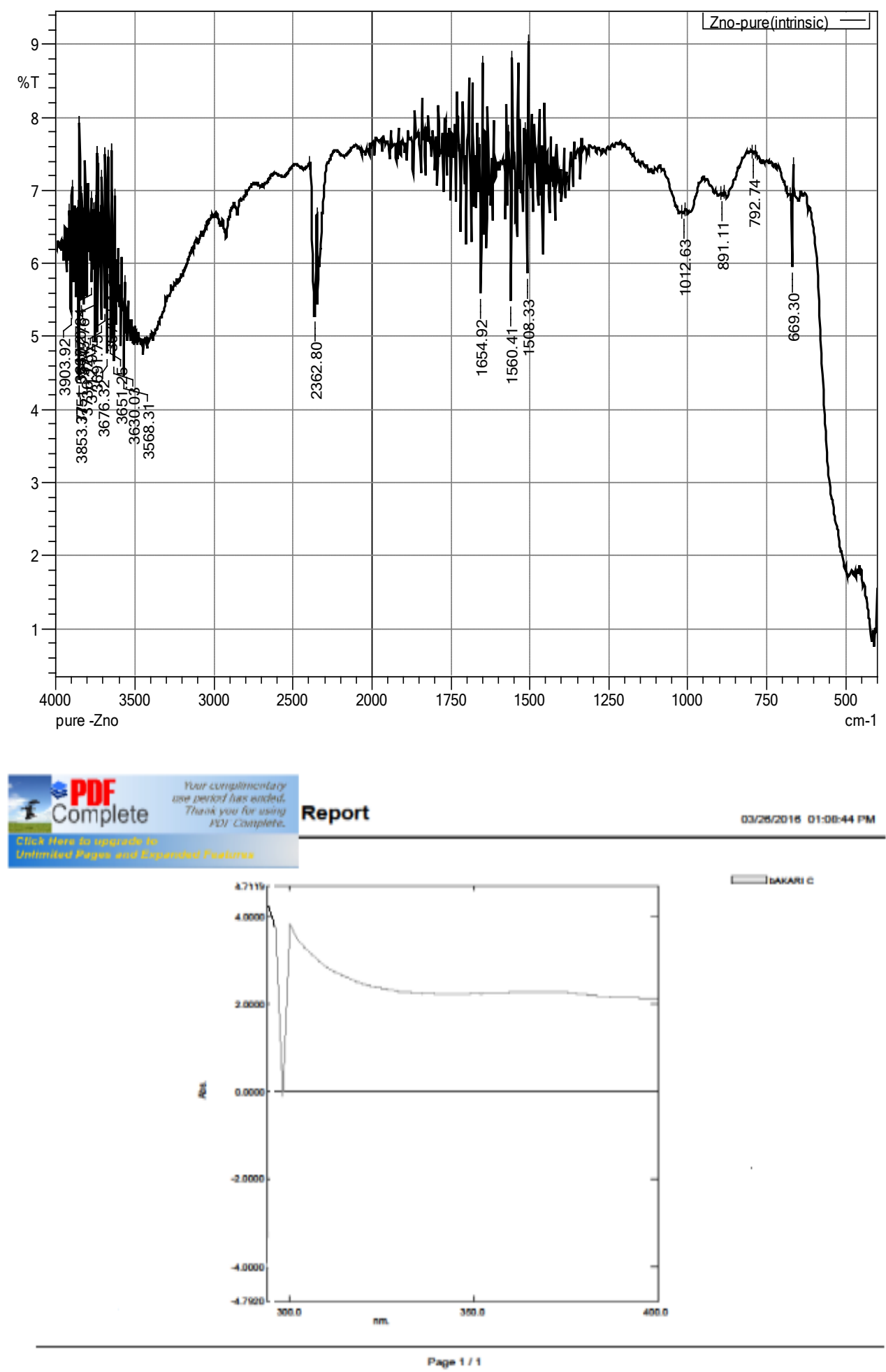

Fig. 2 FTIR spectra and UV-Vis spectra (R) of $\mathrm{ZnO}$ nanoparticles from emulsification of zinc carbamate. 

Embedded onto Zinc Oxide Particles
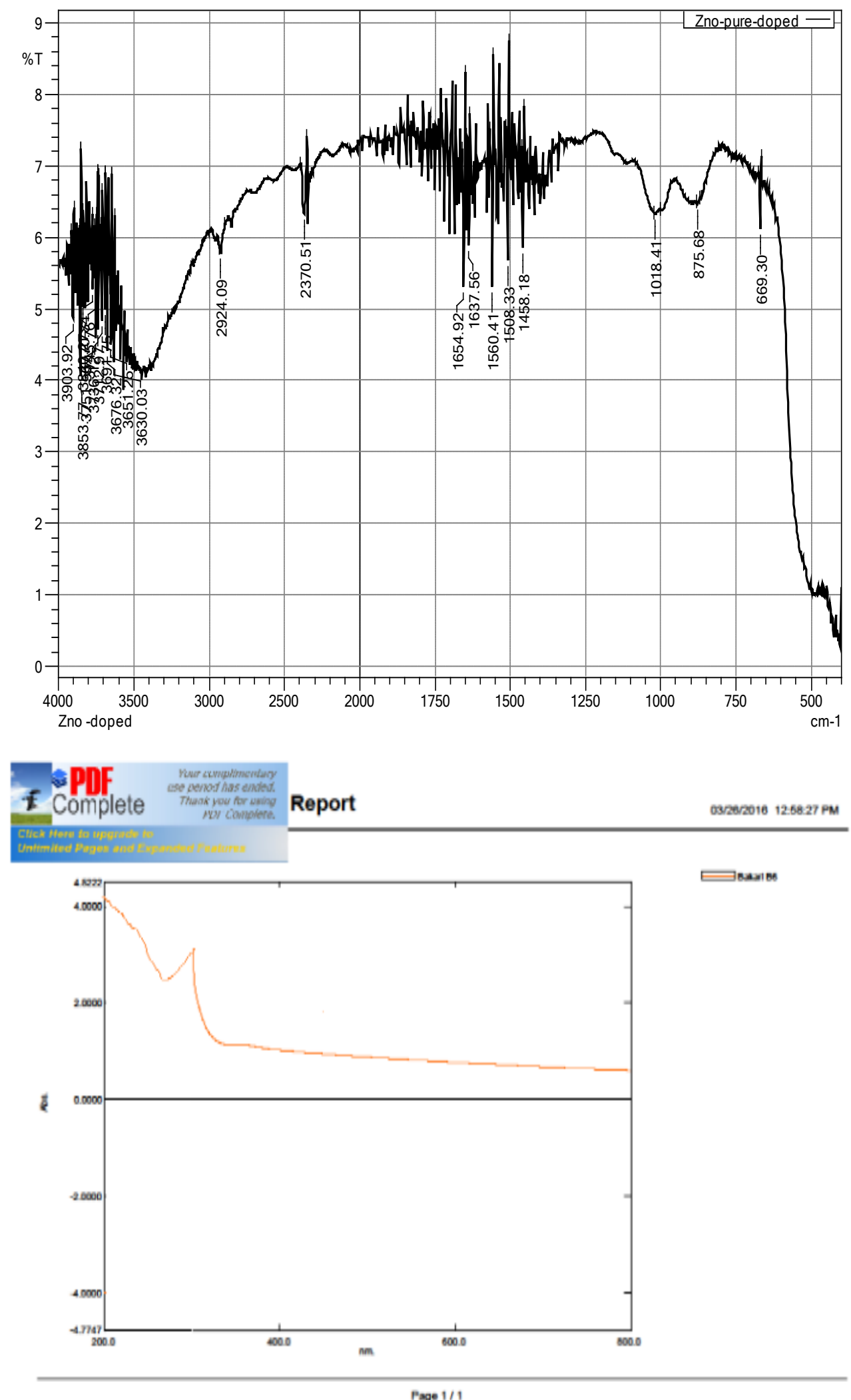

Fig 3 FTIR and UV-Vis spectra of $1 \%$ $\beta$-carotene grafted ZnO nanoparticles. 
slightly blue ended as compared to that of the intrinsic ZnO. The valence bands can be calculated from the heights of the spectra as follows:

$$
\begin{gathered}
E=h c / \lambda \\
E=1,240 / 360 \\
E=3.351 \mathrm{MeV}
\end{gathered}
$$

\subsection{Photodegradation of Organic Solutions}

Fig. 4 indicates the rate at which $1 \mathrm{M}$ acetone is photo degraded to $\mathrm{CO}_{2}$ and $\mathrm{H}_{2} \mathrm{O}$ for samples placed on a background of aluminium coated with $\mathrm{ZnO}$ and grafted $\mathrm{ZnO}$. These samples quickly diminished as they were converted to the more labile $\mathrm{CO}_{2}$ which is gaseous at the conditions of the reaction ( 1 atm pressure and around $33{ }^{\circ} \mathrm{C}$ ). The samples placed on background of $\beta$-carotene only evaporated with time and this can be proved from the time and volume of acetone left after 80 minutes. The sample evaporated is more than that on the blank aluminium foil because of $\beta$-carotene in the aluminium foil which is a conjugated molecule and shows enhanced light absorption [15]. The sample on the blank aluminium foil only slightly decreased under the same conditions as the other samples. Volume decrease on this sample can be wholly attributed to evaporation of volatile acetone and to a less extent blowing off by wind. The rates of photo degradation of acetone by intrinsic and grafted $\mathrm{ZnO}$ can be compared as below:

Average rate of photo degradation by intrinsic $\mathrm{ZnO}$ $=0.1667 \pm 0.00112 \mathrm{~mL} / \mathrm{min}$

Average rate of photo degradation of grafted $\mathrm{ZnO}=$ $0.200 \pm 0.00131 \mathrm{~mL} / \mathrm{min}$

From Fig. 5, it is clear that the rate of photo degradation of $1 \mathrm{M}$ acetone with grafted $\mathrm{ZnO}$ is higher than that of intrinsic $\mathrm{ZnO}$. i.e., $0.140 \mathrm{~mL} / \mathrm{min}<2.00$ $\mathrm{mL} / \mathrm{min}$.

This rate appeared similar to that of $1 \%$ grafted $\mathrm{ZnO}$.

Five percent (5\%) grafted $\mathrm{ZnO}$ appears to be slower than intrinsic $\mathrm{ZnO}$ with their rates being 0.1667 $\mathrm{mL} / \mathrm{min}$ and $0.143 \mathrm{~mL} / \mathrm{min}$ respectively (as seen in Fig. 6). It can thus be concluded that at this rate of

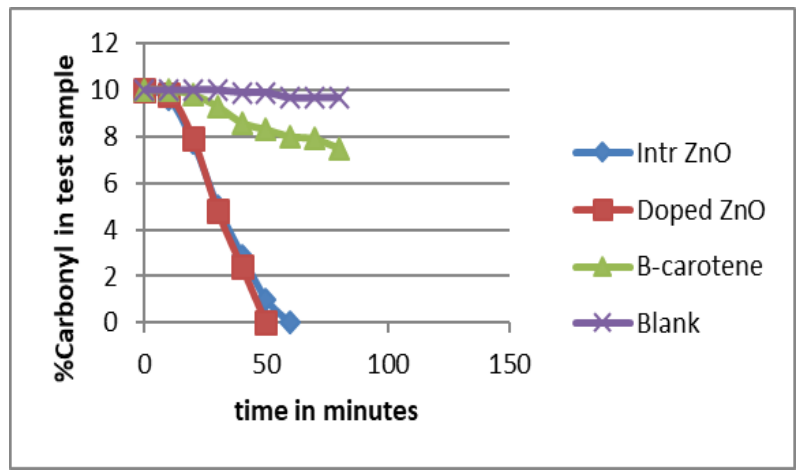

Fig. $41 \mathrm{M}$ acetone when $1 \% \beta$-carotene $\mathrm{ZnO}$ is used.

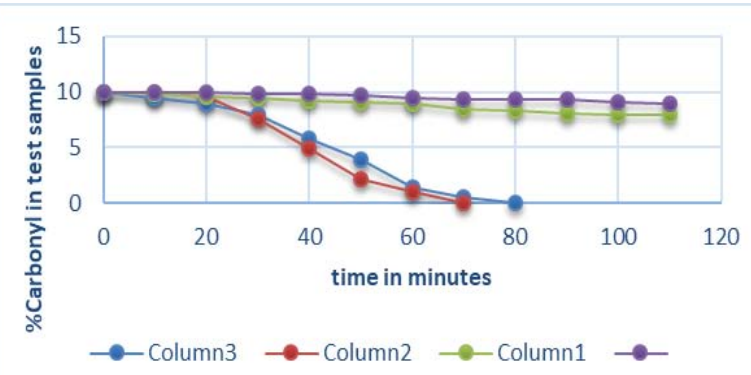

Fig. $51 \mathrm{M}$ acetone when $0.5 \%$ grafted $\mathrm{ZnO}$ is used.

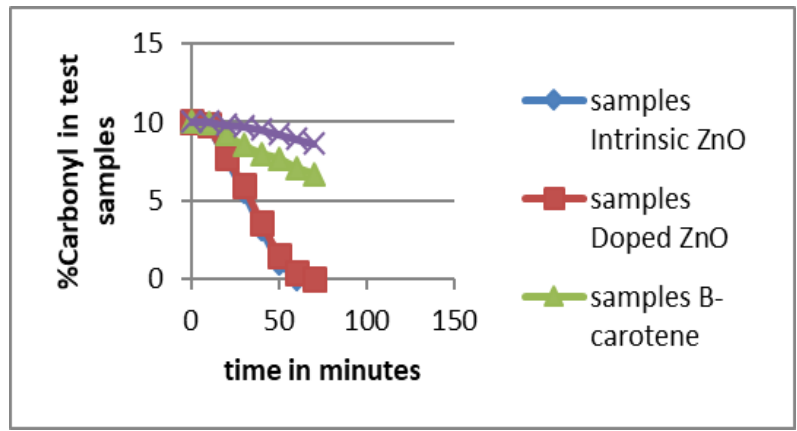

Fig. $61 \mathrm{M}$ acetone when $5 \%$ grafted $\mathrm{ZnO}$ is used.

doping, the carotenoids agglomerate on surface of $\mathrm{ZnO}$ inhibiting its efficiency.

Conc. acetone was quickly degraded as compared to $1 \mathrm{M}$ acetone. This can be attributed to the fact that in concentrated acetone, most of the moles are those of acetone. Therefore, any reaction will directly affect the acetones. The acetone molecules were thus quickly degraded. In dilute acetone, most of the moles are of water thus degradation of acetone only partially accounts for the rate of overall degradation. Thereafter, the water molecules left are more easily evaporated due to the latent heat of photo degradation left behind [2]. The rate of photo degradation using intrinsic and 


\section{Embedded onto Zinc Oxide Particles}

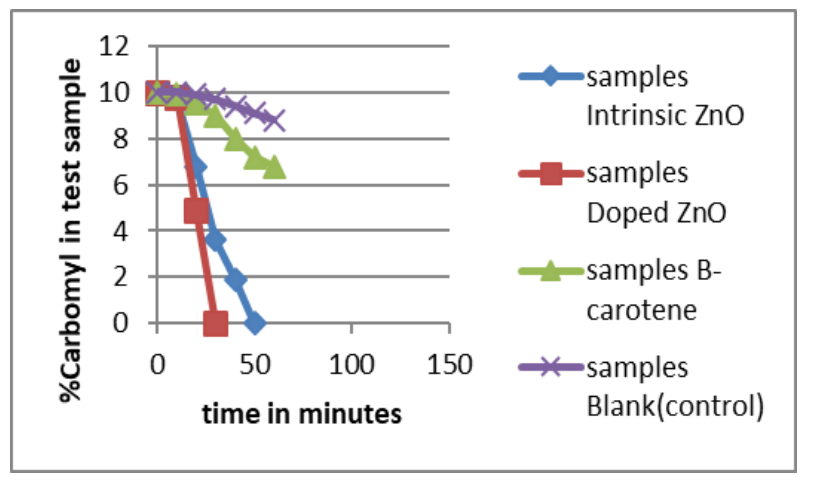

Fig. $7 \quad 14.5 \mathrm{M}$ acetone with $1 \%$ grafted $\mathrm{ZnO}$. grafted $\mathrm{ZnO}$ at this concentration is 0.250 and 0.333 $\mathrm{mL} / \mathrm{min}$ respectively. Fig. 7 shows that the order of rate of photodegradation is not affected by increasing the concentration of acetone and maintaining grafting level at $1 \%$.

\subsection{Photodegradation (Decolorization) of Colored Dyes}

2,4-DNP-Hydrazine decolorization is one of the best indicators for a good photocatalyst. In following,

3.2.1 Using $100 \%$ v/v Methyl Blue Indicator

Initially,

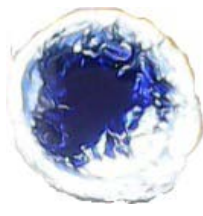

Blank (A)

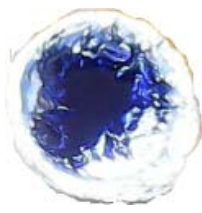

Intrinsic (B)

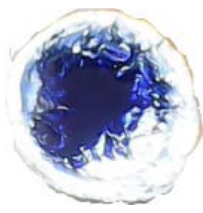

Grafted (C)
After 30 minutes

3.2.2 Decolorization of 1\% w/v 2,4-DNP Hydrazine Initially,

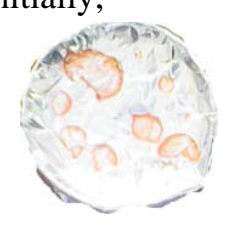

Blank

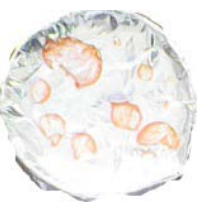

Intrinsic

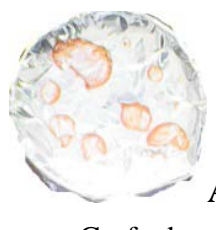

Grafted

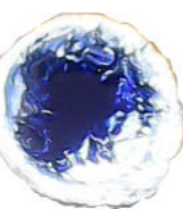

A

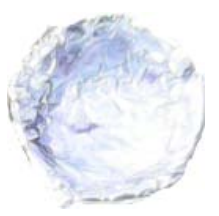

B

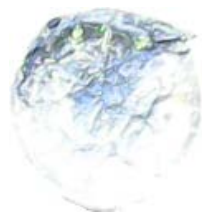

C

\subsection{Photodegradation of Organic Wastewater (Sewerage Water)}

Table 1 below shows the percentage of carbonyl removal from waste water when natural light is used:

Table 1 Photodegradation of sewerage water carbonyls using sunlight.

\begin{tabular}{llll}
\hline \% Carbonyl removal after 40 minutes & Blank & Intrinsic ZnO & $1 \%$ grafted ZnO \\
\hline Sample $A_{1}$ & 0.3 & 18.0 & 27.0 \\
Sample $_{2}$ & 0.0 & 22.0 & 25.0 \\
Sample $_{3}$ & 1.7 & 26.0 & 32.0 \\
Sample $_{4}$ & 1.0 & 28.0 & 28.0 \\
Sample $A_{5}$ & 3.0 & 29.0 & 31.0 \\
Sample $B_{1}$ & 1.0 & 12.0 & 15.0 \\
Sample $B_{2}$ & 0.0 & 33.0 & 42.0 \\
Sample $B_{3}$ & 1.0 & 15.0 & 21.0 \\
Sample $C_{1}$ & 0.0 & 45.0 & 47.0 \\
Sample $C_{2}$ & 1.0 & 14.0 & 17.0 \\
Average & 0.9 & 24.2 & 28.5 \\
Median & 1.0 & 24.0 & 27.5 \\
Variance & 0.876 & 103.511 & 104.528 \\
Standard deviation & 0.936 & 10.174 & 10.224 \\
\hline
\end{tabular}


Table 2 Photodegradation of sewerage water carbonyls using UV-lamp.

\begin{tabular}{ll}
\hline Sample & Average \% carbonyl removal by $1 \% \beta$-carotene ZnO after 30 minutes in UV lamp \\
\hline Blank & $0.00 \pm 0.00 \%$ \\
Sample A & $24.12 \pm 0.342 \%$ \\
Sample B & $24.12 \pm 0.333 \%$ \\
Sample C & $18.06 \pm 0.671 \%$ \\
\hline
\end{tabular}

Initially,

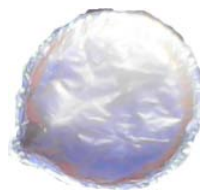

Blank

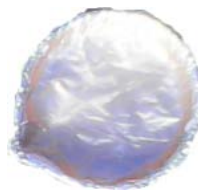

Intrinsic

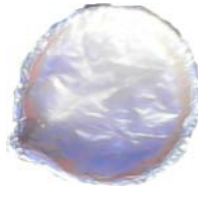

Grafted
After 30 minutes

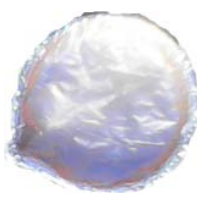

Blank

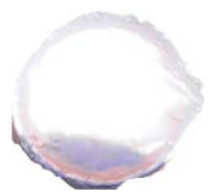

Intrinsic

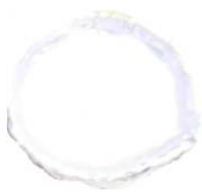

Grafted

Fig. 8 Sewerage water samples $\left(C_{1}\right)$ which were barge in color but the samples in intrinsic and grafted $\mathrm{ZnO}$ decolorized after sunlight exposure.

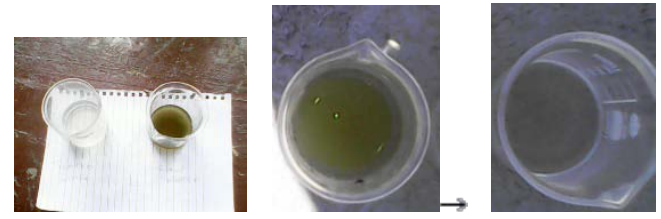

Fig. 9 A photograph to illustrate raw (left) and photo degraded (right) sewerage water.

there is a clear resolution between the samples on intrinsic and grafted $\mathrm{ZnO}$ with the grafted sample showing more color change from red to yellow. The sample on blank remained red all through.

Table 2 above shows that sewage samples can also be degraded using light from UV-lamp source. The students $t$-test was calculated as $t=\frac{[x 1-x 2]}{[A * B]}$ where $x_{1}$ and $x_{2}$ are the sample means for intrinsic $\mathrm{ZnO}$ and $1 \%$ $\beta$-carotene grafted ZnO data sets, $A=n_{1}+n_{2} / n_{1} n_{2}, B=$ $\left[\left(n_{1}-1\right) S_{1}^{2}+\left(n_{2}-1\right) S_{2}^{2}\right] /\left(n_{1}+n_{2}-1\right)$.

$n_{1}+n_{2}-2$ gives the degree of freedom for the two data sets. In this test, $t=1.3333$ and the tabulated value for 18 degrees of freedom at $p=0.10$ is 1.330 . Fig. 8 above shows the color changes that take place when sewage effluent is photodegraded. Use of grafted zinc oxide was found to effectively purify the water; in the process its color changing from green to clear solution as shown in Fig. 9 above.

\section{Conclusion}

$\beta$-carotene was extracted from cacti Opuntia stricta seeds and carrot peels using methanol and grafted chemically by Molecular Layer Doping method at $180{ }^{\circ} \mathrm{C}$ onto zinc oxide particles prepared by emulsification of zinc carbamate solution to $\mathrm{pH} 12$. The resulting grafts turned from white to slightly orange. FTIR spectra resulted in an additional peak at around 1,435 nm, assumed to correspond to $\mathrm{Zn}-\mathrm{C}$ organometallic bond. The conjugation system of $\beta$-carotene introduces positive holes in the conduction band allowing electrons in valence band to skip to higher energy states thus lowering the band gap of ZnO. UV-Vis spectra indicate a slight blue shift and thus a corresponding decrease in band gap from 3.5 $\mathrm{eV}$ to $3.4 \mathrm{eV}$.

Zinc oxide grafted at between $0.5 \%$ and $1 \%$ using $\beta$-carotene was more reactive as compared to intrinsic zinc oxide nanoparticles while grafting $\mathrm{ZnO}$ at $5 \%$ level was slower due to agglomeration of carotenoids on $\mathrm{ZnO}$ surface. Blank aluminium surface was least photoreactive. Carbonyl containing compounds (acetone, formaldehyde and 98\% ethanol) were successfully degraded against control experiments containing blank aluminium foils and a clear disparity in photo degradation was observed. An average 
degradation rate of $0.2 \pm 0.015 \mathrm{~mL} / \mathrm{min}$ for $0.5-1 \%$ grafted $\mathrm{ZnO}$ and $0.16 \mathrm{~mL} /$ minute for intrinsic $\mathrm{ZnO}$ was recorded against that of $0.01 \mathrm{~mL} / \mathrm{min}$ for blank samples, clearly indicating disparity in photo degradation when a $10.00 \mathrm{~mL}$ volume placed in a 10 $\mathrm{cm}$ diameter reactor. Samples degraded with 5\% grafted $\mathrm{ZnO}$ had degradation rates of as low as $0.11 \pm$ $0.005 \mathrm{~mL} / \mathrm{min}$.

Photodegradation of colored methyl blue, orange food color and 2,4-DNP hydrazine clearly indicated alterations of conjugation. Decolorization of 2,4-DNP-Hydrazine from red to orange after 15 minutes exposure to sunlight on a grafted $\mathrm{ZnO}$ background indicated photo catalytic activity of this compound. Colored wastewater was also decolorized after 45 minutes exposure on the same reactor.

Sewage water was tested for carbonyl concentration before and after degradation and a mean 28.5\% removal rate was recorded in a 45 minutes exposure time. Samples degraded by intrinsic $\mathrm{ZnO}$ registered a removal rate of $24.5 \%$ while those on blank had a mean removal of $0.6 \%$, attributed to loss of biomolecules such as bacteria due to exposure to UV light. The enhanced efficiency of $\beta$-carotene grafted $\mathrm{ZnO}$ as compared to that of intrinsic $\mathrm{ZnO}$ by $4.0 \%$ is due to decreased band gap as a result of p-doping.

\section{Acknowledgement}

The authors thank Maasai Mara University for providing laboratory material and funds support which boosted the research activity. Also, many appreciations go to JASCO Co Ltd for the assistance in spectrophotometric analysis. The researchers appreciate the support received from The Centre for Innovation, New and Renewable Energy Department (CINRE) of Maasai Mara University, Kenya.

\section{References}

[1] Akpan, U. G., and Hameed, B. H. 2009. "Parameters Affecting the Photocatalytic Degradation of Dyes Using $\mathrm{TiO}_{2}$-Based Photocatalysts: A Review." Journal of Hazardous $\quad$ Materials $170 \quad$ (2-3): $\quad$ 520-9. http://doi.org/10.1016/j.jhazmat.2009.05.039.

[2] Ma, L., Jia, I., Guo, X., and Xiang, L. 2014. "Catalytic Activity of Ag/SBA-15 for Low Temperature Gas Phase Selective Oxidation of Benzyl Alcohol to Benzaldehyde.” Chinese Journal of Catalysis 35 (2): 108-19. http://doi.org/10.1016/S1872.

[3] Martinez, T., Bertron, A., Ringot, E., and Escadeillas, G. 2011. "Degradation of NO Using Photocatalytic Coatings Applied to Different Substrates.” Building and Environment $\quad 46 \quad$ (9): $1808-16$. http://doi.org/10.1016/j.buildenv.2011.03.001.

[4] Myint, M., Al-Harthi, S. H., and Dutta, J. 2014. "Brackish Water Desalination by Capacitive Deionization Using Zinc Oxide Micro/Nanostructures Grafted on Activated Carbon Cloth Electrodes.” Desalination 344 (July): 236-42. http://doi.org/10.1016/j.desal.2014.03.037.

[5] Norziah, M. H., Nuraini, J., and Lee, K. Y. 2009. "Studies on the Extraction and Characterization of Fish Oil from Wastes of Seafood Processing Industry.” Asian Journal of Food and Agro-Industry 2 (04): 959-73.

[6] Mondal, K., and Sharma, A. 2014. "Photocatalytic Oxidation of Pollutant Dyes in Wastewater by $\mathrm{TiO}_{2}$ and ZnO Nano-Materials-A Mini-review.” The National Academy of Sciences India (NASI) 5: 36-72.

[7] Myilsamy, M., Mahalakshmi, M., Murugesan, V., and Subha, N. 2015. "Enhanced Photocatalytic Activity of Nitrogen and Indium Co-grafted Mesoporous $\mathrm{TiO}_{2}$ Nanocomposites for the Degradation of 2,4-dinitrophenol Under Visible Light.” Applied Surface Science 342: 1-10. http://doi.org/10.1016/j.apsusc.2015.03.017.

[8] Kobayashi, M., and Kalriess, W. 1997. "Photocatalytic Activity of Titanium Dioxide and Zinc Oxide." Cosmetics Toiletries ${ }^{\circledR}$ Magazine/83 112 (June): 83-5.

[9] Shi, H. 2002. "Industrial Wastewater-Types, Amounts and Effects.” Point Sources of Pollution: Local Effects and Its Control 1: 1-6.

[10] Kashif, M., Ali, M. E., Usman Ali, S. M., Foo, K. L., and Hashima, U. 2013. "Morphological, Structural, and Electrical Characterization of Sol-Gel-Synthesized $\mathrm{ZnO}$ Nanorods.” Journal of Nanomaterials 139: 3-6.

[11] Kołodziejczak-Radzimska, A., and Jesionowski, T. 2014. "Zinc Oxide-From Synthesis to Application: A Review." $\begin{array}{llll}\text { Materials } & 7 & \text { (4): }\end{array}$ http://doi.org/10.3390/ma7042833.

[12] Ogales, S. B. 2005. Thin Films and Heterostructures for Oxide Electronics. 1st ed. Vol. 97. New York: Springer, 212-23.

[13] Kim, J. K., Lee, J. L., Lee, J. W., Shin, H. E., Park, Y. J., and Kim, T. 2003. "Mechanism for Ohmic Contact Formation of Oxidized Ni/Au on p-Type GaN.” Journal of Applied Physics 94: 23-6. 
[14] Sengupta, D., Das, P., Kasinadhuni, U., Mondal, B., and Mukherjee, K. 2014. "Zinc Oxide Photo-Anode Based Chlorophyll Sensitized Solar Cell Zinc Oxide Photo-Anode Based Chlorophyll Sensitized Solar Cell.” Renewable and Sustainable Energy Reviews 52 (October): 54-64.

[15] Wingqvist, A., and Work, D. 2011. "Extraction, Isolation and Purification of $\beta$-carotene.” Diploma work, Karlstads Universitet 65188 Karlstad, 23-31.

[16] Kaneva, N. V., and Dushkin, C. D. 2011. "Preparation of Nanocrystalline Thin Films of ZnO by Sol-Gel Dip Coating.” Bulgarian Chemical Communications 43 (2): 259-63. 